\title{
A Point of Interest Data Method of Pingshan Village's Spatial Pattern Coupling with Business Form
}

\author{
Li Chuntao ${ }^{1}$, Bi Huiyu ${ }^{1}$, Chen Zhenhua ${ }^{2, *}$ \\ ${ }^{1}$ School of Forestry and Landscape Architecture, Anhui Agricultural University, Hefei, \\ 230031, China \\ ${ }^{2}$ School of Urban Construction, Anhui Xinhua University, Hefei, 230031, China
}

Received: January 29, 2021. Revised: July 26, 2021. Accepted: August 23, 2021. Published: August 25, 2021.

\begin{abstract}
In the context of the rapid development of China's urbanization economy and the current situation of "hollow villages"era., how to effectively inherit and protect the Chinese traditional villages as cultural heritage is an important issue for China's beautiful rural construction. The economic development of villages is based on the reasonable configuration of business, as an important carrier of the layout of the format , the architectural space and street space of the village are linked together for analysis and research, so as to achieve the "win-win" effect of high-quality business form and the rational use and protection of historical building space.This paper takes Pingshan Village, a famous historical and cultural village in Yi county, China, as the research object, collects data through historical record, on-site investigations and interviews, and uses geographic information technology, point of interest combing and spatial syntax analysis to study the spatial characteristics of the current status of the Pingshan Village's commercial concentrated water street. Besides, this paper makes quantitative analysis of the number of business forms in JiyangXi water street, spatial analysis of the commercial layout, and fixed-point analysis of the flow of people. With the results above, this paper takes correlation analysis on the results of analyzing spatial characteristics and the layout of business forms, draws up the advantages and disadvantages of the main commercial space layout of Pingshan Village as well as the optimization strategy, thereby reaches the design suggestions on the adjustment of the business forms in different spaces in traditional village planning.
\end{abstract}

Keywords - traditional villages; spatial analysis; Jiyangxi water street; business forms; optimized configuration; POI; spatial characteristics; rural revitalization

\section{INTRODUCTION}

$\mathrm{Y}$ ixian County locates in the south of Anhui Province, with its unique geographical and natural environment in the southern Anhui mountainous area, combined with profound cultural heritage, it has world-class and provincial-level historical and cultural heritages such as Hongcun Village, Xidi Village, Nanping Village., Guanlu Village, Pingshan Village and Bishan Village. These ancient villages show the unique charm of Huizhou in terms of natural and human landscape features. Yixian County also has many cultural relics protection units, which are precious historical and cultural heritages and "museums" of Huizhou culture.

As an important part of the construction of beautiful villages, traditional villages are the main place of production and inheritance of traditional Chinese culture. They carry the rich and colorful national culture, reflect the basic living mode of habitation, show the various forms of villages, and contain the traditional ecological development view[1].

In the context of rural revitalization and construction of beautiful villages across the country, traditional villages have been disturbed and affected by many factors on the road of inheritance and protection. There are problems that need to be solved urgently in traditional villages at present. For example, some of the ancient buildings in the traditional villages have been rebuilt due to the needs of daily life and business conditions, and some of the ancient buildings collapsed due to unmanned use for a long time. Moreover, rural tourism and factory development have caused serious pollution of the soil and hydrological environment in traditional ancient villages[2]. Also, the living environment and routine of traditional ancient villages have been seriously disturbed and affected, and traditional ancient villages and buildings have been overexploited. In the face of these problems, the research and analysis of the spatial peculiarities of ancient villages, one of the essence of historical culture, combined with the study of the effective inheritance of historical buildings as an important carrier of modern business development, and the reasonable distribution of commercial business according to the characteristics of space, put forward the optimization strategy of linkage development between the two. It is not only to effectively control the rate of destruction of traditional villages, 
under the background of the policy of rural revitalization, but also to give full play to and make use of the characteristics and advantages of the ancient village to achieve the research purpose of "invigorating" the ancient village.

\section{OVERVIEW OF PINGSHAN VILLAGE}

Pingshan Village is one of the provincial historical and cultural heritages of Yixian County, a famous historical and cultural village in China, and a typical ancient village in southern Anhui Province. Pingshan Village is located at the southwestern foot of Huangshan Mountain, about 4 kilometers away from the downtown of Yixian County, Huangshan City. It has a history of about 1,100 years (see Figure 1). Yixian County, where Pingshan Village is located, is one of the core areas of Huizhou culture. Pingshan Village is adjacent to the foothills of Pingfeng Mountain and Jiyang Mountain. The water system of Pingshan winds through the village from Jiyang River. Pingshan Village has a high density of ancient buildings and concentrated land, where tea trees are mostly used as cash crops.

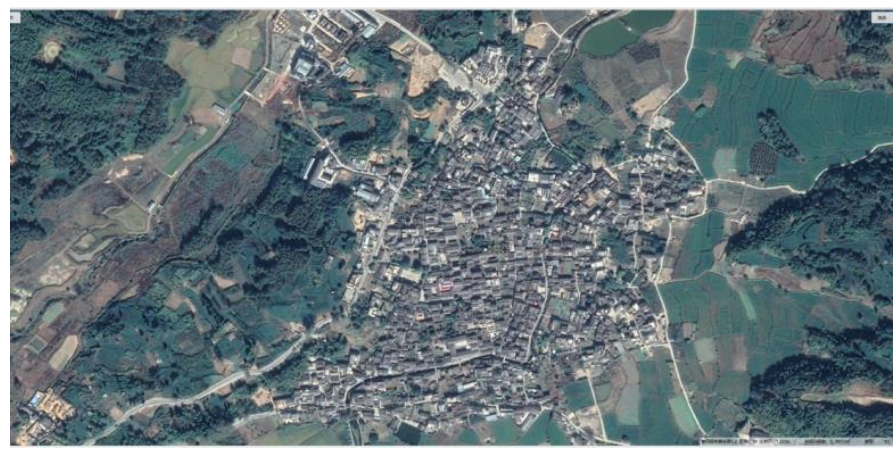

Fig. 1 Satellite picture of Pingshan Village

The network of streets and lanes of Pingshan Village is laid out by the development of ancient villages. Field investigation shows that despite of seven ancient ancestral halls, most of the ancient buildings from the Ming and Qing Dynasties in the village are still habitable, and a quarter of the ancient buildings are seriously damaged. The internal streets and lanes of Pingshan Village are well preserved, which provides a good foundation for the layout of the business forms in the village. Due to the adjustment of tourism industry, many buildings in the village were damaged.

Pingshan Village is an important art sketching base in southern Anhui Province. It has unique tourism development, that is, the peak tourist season of Pingshan Village is mostly determined by the opening time of art colleges and universities (mostly in March, April and September). The characteristics of the student sketching base are long operation cycle, high frequency of use, concentration of personnel, large number of people, etc. Therefore, Pingshan Village's business forms centered "eating, drinking, entertainment, and shopping"which matching student services, among which are mainly business stores, showing typical self-organization characteristics of the private sector. However, in the process of village development, many shortcomings and problems to be solved have emerged, such as individual activities affecting the original appearance of the ancient village (most of the villagers have knocked down and rebuilt ancient buildings from the Ming and Qing dynasties to accommodate as many visitors as possible because of the development of sketching accommodation bases), commercial tendencies causing utilitarianism (most of the businesses in the village are aimed at the economies of the student sketching flow, especially bars, barbecue stalls and other businesses that do not fit in with the background of the historical and cultural village), and the imbalance of the living structure of the ancient village residents (most of the residents rely on farming and tea picking as their main economic income situation, but the village is occupied by sketching students and commercial services for sketching, the normal life of the residents is restricted, and the village has no venue for the residents to relax and communicate).

\section{SPATIAL PATtERN AND SPATIAL ANALYSIS OF PINGSHAN VILLAGE}

Pingshan Village is located at $118^{\circ} 1^{\prime}$ east longitude and $30^{\circ} 1^{\prime}$ north latitude, the foothills of Pingfeng Mountain and Jiyang Mountain, where about 4 kilometers far from northeast of Yixian County, Huangshan City. Jiyang River runs through the village from north to south, and the village is located along both sides of the river. Located in the mountains of southern Anhui, Pingshan Village belongs to the northern subtropical humid monsoon climate where the four seasons are distinct and the climate is mild. It has long winter and summer, short spring and autumn. The annual average temperature is $15.5^{\circ} \mathrm{C}$, the average temperature of the hottest month (July) is $27.1^{\circ} \mathrm{C}$, and the coldest month ( 1 Month) The average temperature is $3.7^{\circ} \mathrm{C}$.

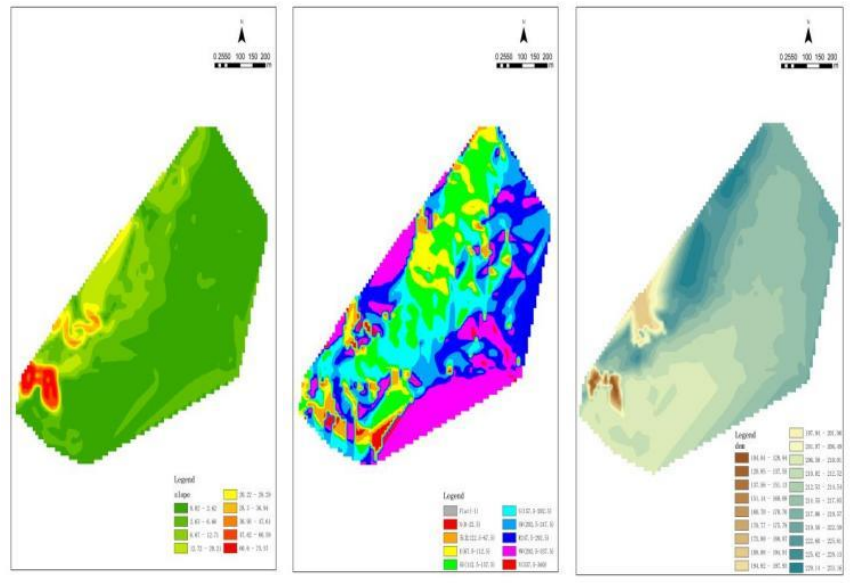

Fig. 2 Topographic and geomorphological analysis map of Pingshan Village

The slope value of Pingshan Village ranges from $0.02^{\circ}$ to $73.57^{\circ}$. It can be seen from Figure 2 that the slope within the village is low and the slope of surrounding area is high, presenting a topographical form with high slopes on both sides and low in the middle. In terms of aspect analysis, the different color blocks in Figure 2 indicate the orientation of the slope in the area which directly affects factors such as daylighting, microclimate, humidity, etc. The overall village orientation of Pingshan Village is south and southeast, which means high 
lighting, suitable for drying and high livability. The slopes of the surrounding mountains are mainly towards the west and southwest, and the sunshine time is relatively long, which is suitable for planting economic crops such as high mountain tea and bamboo. The tea industry and tea culture in Pingshan Village are well developed due to the influence of the mountainous terrain. Through the digital elevation DEM analysis in arcGIS[3-5], it can be seen that the elevation of Pingshan Village and the surrounding mountains is between 104.84 meters and 233.16 meters. The terrain is low in the east and west, high in the middle parts. Surface runoff gathers from north to south and the mountains around the village form a natural protective barrier of settlements, showing a clustered topography. Moreover, the Jiyang River water system in the middle is like a blue ribbon that firmly "ties" Pingshan Village between Pingfeng Mountain and Jiyang Mountain. From the perspective of Feng Shui, it can be seen that the layout of the village and the collection of sites reflect the meaning of "gathering treasures". From the perspective of defense thinking, it can be seen that the overall defensiveness of the village is very high, and the natural resources of surrounding can satisfy the life and production activities of the village. The village presents a quiet and relatively saturated life all year round, but since the development of student sketching as the main economic format, the original state of Pingshan Village has been broken. In order to cater to the development of the economic format and economic transformation, the villagers and businesses shows "one-sided" situation of "fading away the old and welcoming the new" towards the development of the villiage.

By importing the overall POI data of Pingshan Village obtained from Google Maps into ArcGIS for calculation and analysis. The calculation formula is

$$
f(x)=\frac{1}{\mathrm{nh}_{n}} \sum_{i=1}^{n} k_{0}\left(\frac{\left|x-x_{i}\right|}{h_{n}}\right)
$$

In the formula, $n$ is the number of samples; $h_{n}$ is the bandwidth, that is, the search radius; $k\left(\frac{\left|x-x_{i}\right|}{h_{n}}\right)$ is the kernel function.

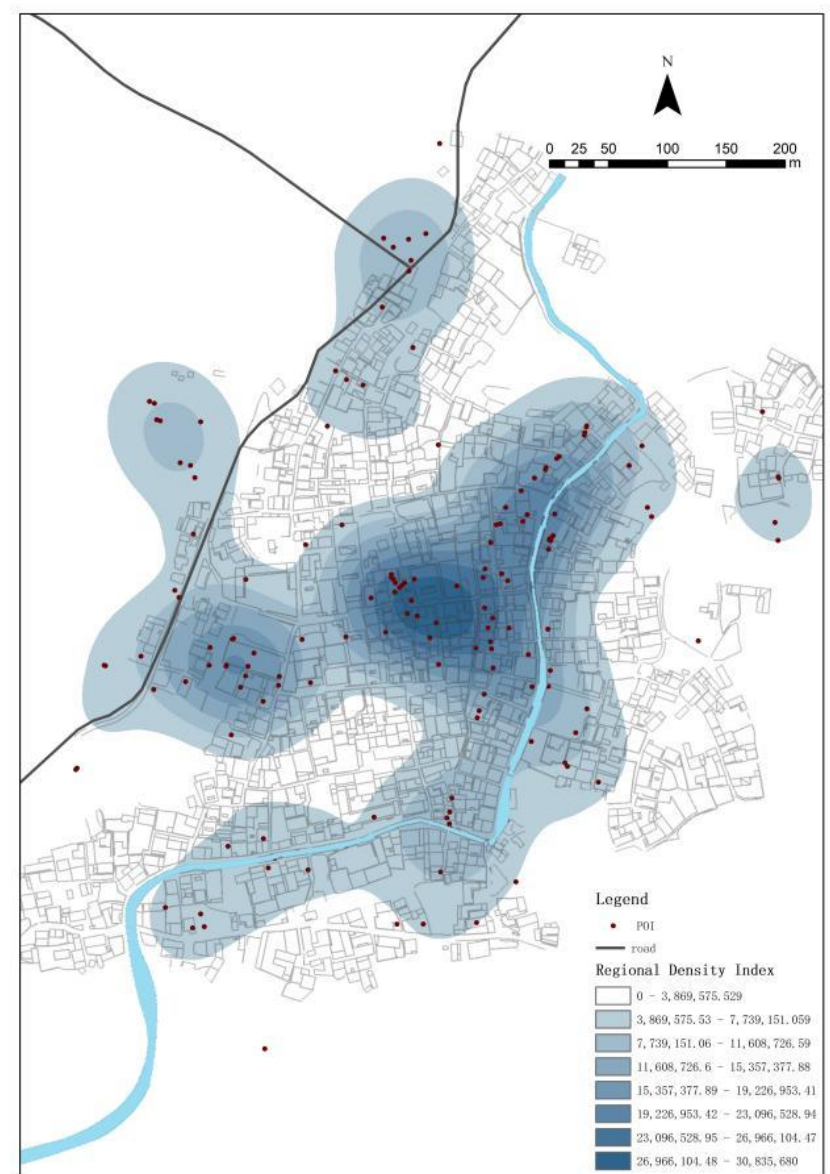

Fig. 3 Nuclear density analysis diagram of Pingshan Village

In the nuclear density analysis legend (see Figure 3), it can be seen from the regional density index that the comprehensive business forms radiate divergently along Jiyangxi water street in Pingshan Village. The main forms of business are more concentratedly distributed on both sides of the main road along the periphery of the village and on both sides of Jiyangxi water street. Radiating with 90 meters around the pixel as the search radius (and the bandwidth is 90 meters) in the analysis diagram (Figure 3), the darker the area, the more points of interest, and the higher the density of business layout[6]. It can be seen from the figure that in Pingshan Village, the most concentrated points of interest are on the west side of Jiyangxi water street, near the Imperial Guard scenic spot, and the entrance of the main road outside the village. Combined with the analysis of slope and spatial opening and closing, it is meaningful to study Jiyangxi water street as the core area of business development.

Table 1. POI data classification of Pingshan Village

\begin{tabular}{ccc}
\hline $\begin{array}{c}\text { Number: } \\
\text { Classification }\end{array}$ & amount & POI data \\
\hline $\begin{array}{c}\text { a: Catering } \\
\text { Services }\end{array}$ & 52 & $\begin{array}{c}\text { Pastry shop, fast food } \\
\text { restaurant, coffee shop, } \\
\text { cold drink shop, Chinese } \\
\text { restaurant }\end{array}$ \\
$\begin{array}{ccc}\text { b: Tourist } \\
\text { Sites }\end{array}$ & 5 & $\begin{array}{c}\text { Scenic spots, tourist } \\
\text { attractions }\end{array}$
\end{tabular}




$$
\text { c: Public }
$$

Utilities

3

Public toilet

$$
\mathrm{d} \text { : }
$$

Coorperation

f:

Transportation

facilities

g: Financial

Service

h: Technology

and Culture

Service

i: Car Service

$\mathrm{j}$ : Business

Residence

k: Domestic

Services

1: Sports and

Leisure

Services

$\mathrm{m}$ :

Government

Agencies and Social

Organizations

$\mathrm{n}$ :

Accommodati

on Service base schools office for sketch
Company enterprise, other agriculture, forestry, animal husbandry and fishery

Convenience stores, supermarkets, building materials and hardware, stationery stores

Public parking lot, etc.

Rural commercial bank

Technological and cultural venues, training institutions, primary

Charging station

Business hotel, etc.

Service industry, ticket

Leisure venues, entertainment venues, $\mathrm{KTV}$, sports venues

$4 \quad$ Pubilic institutions

Hotels, guest houses, accommodation bases

The POI data classification of Ping Shan Village in Table 1 shows that in the development of the traditional ancient village with deep profound history and culture, the positioning of the tourism mode of the sketching base makes it a "tourist village" integrating "catering" + "accommodation" + "shopping". "The "tourism village". The economic development brought by this development status quo is deformed, no connotation, rapid, non-circular state, because the significance of the student sketching base lies in the historical precipitation and cultural value of the village, and not the value of service support. Many ancient building holders value the short-term benefits of sketching service and do not hesitate to destroy or even knock down and rebuild the historical buildings left in the Ming and Qing dynasties; many commercial operators pursue the maximum benefit of the business economy, such as bars and concert halls are also "crazy at night", the historical and cultural villages, the cultural deposits in the hometown of Huizhou merchants are modern In the off-season of tourism, the village is left with a cluttered environment and a sense of "zero" existence of the people in the village. These businesses are haphazardly distributed in various streets and alleys of Ping Shan Village, and mainly distributed on both sides of the central
Jiyang Creek Water Street. Contemporary college students come to the village to receive the baptism of history and culture, respect and admire the traditional Chinese culture, inherit and spread the essence of Chinese historical architecture, but in the present village more experience the satisfaction brought by tourism, and there is a deviation from the original intention of sketching. To achieve effective and sustainable inheritance and protection of traditional villages, while developing tourism, making good use of the street space, traditional architecture space and connotation, setting and laying out the business in a reasonable and orderly way, optimizing and expanding the business type, and integrating the cultural in situ nature of traditional Huizhou culture is the ultimate goal of research and analysis.

\section{ANALYSIS OF BUSINESS FORM STRUCTURE OF PINGSHAN VILLAGE}

As a famous Chinese historical and cultural village, Pingshan Village has a history of more than a thousand years. It is backed by Pingfeng Mountain and nestled in Jiyang Mountain. Jiyang River runs through the village forming a beautiful water street with strong flavor of life. The historical buildings and historical culture in the village are the business cards that attract tourists, and they are also the "textbooks" for sketching education in colleges and universities across the country. Statistics shows that since 2000, Pingshan Village as a sketching base has carried a passenger flow of about 10,000 students at the same time period in each peak season. This is a test of a new historical period for the ancient village. Residents' lives have been affected, the economic structure of the village has been changed, and the intrusion and assimilation of foreign cultures are not all negative, but also shows some advantages that activating the "silent" state of traditional villages. Besides, the integration of ancient buildings and modern culture in ancient villages greatly increased the activity of wise villagers.

In the field survey and the data collected by the Pingshan Village Ticket Center (see Table 2), the annual ticket sales from 2015 to 2020 were compared vertically, and the proportion of student ticket data in the total ticket sales was compared horizontally[7]. It can be seen from Table 1 that due to the impact of the coronavirus epidemic in 2020, tourism has severely affected. However, from 2015 to 2019, the amount of tourist ticket sales in Pingshan Village has continued to increase, and the capacity for tourism of Pingshan Village has gradually developed. From the perspective of tourist structure, student sketching activities accounted for $89.1 \%$ in 2015 , but in 2019 , it can be seen that the structure has gradually changed, and the proportion of student sketching has dropped to $70.6 \%$, that is, $29.4 \%$ of tourists are social tourists. It can be explained that the tourist structure of Pingshan Village is changing year by year, and the commercial format of traditional villages is also undergoing "deformed" changes.

Table 2 Statistics of Tourist Tickets in Pingshan Village

\begin{tabular}{cccc} 
Years & $\begin{array}{c}\text { Total } \\
\text { ticket } \\
\text { amount }\end{array}$ & $\begin{array}{c}\text { Student } \\
\text { ticket } \\
\text { amount }\end{array}$ & $\begin{array}{c}\text { Ratio of } \\
\text { student }\end{array}$ \\
& & & \\
\hline
\end{tabular}




\begin{tabular}{cccc}
\hline & $\begin{array}{c}\text { (ten } \\
\text { thousan } \\
\text { d) }\end{array}$ & $\begin{array}{c}\text { (ten } \\
\text { thousand) }\end{array}$ & $\begin{array}{c}\text { tickets to } \\
\text { total amount }\end{array}$ \\
\hline 2015 & 5.5 & 4.9 & $89.1 \%$ \\
2016 & 6 & 5.2 & $86.7 \%$ \\
2017 & 9.2 & 6.7 & $72.8 \%$ \\
2018 & 9.6 & 7 & $72.9 \%$ \\
2019 & 10.2 & 7.2 & $70.6 \%$ \\
2020 & 4.9 & 4 & $81.6 \%$ \\
\hline
\end{tabular}

Combining field research and relevant data provided by Hongcun Township Office of Industry and Commerce (see Table 3) in December 2020, this paper took Jiyangxi water street in Pingshan Village as the research object, and divided the water street into three sectionts: the head of street (from Xiaqiao Pavilion to Shangqiao Pavilion), the middle street (from Xiaqiao Pavilion to Tiandeng Lane) and the end of the street (from Tiandeng Lane to the end of the street) as sample. There are a total of 102 commercial stores in the street, including 21 in the head of street, 62 in the middle, and 19 at the end of the street. Commercial shops are concentrated in the middle of the street, and the middle part of the street is also the most accessible area through spatial analysis.

The business format functions are divided into three categories: facing tourists, facing tourists and residents, and facing residents. Table 2 shows that there are 75 commercial format shops facing tourists, accounting for $73.5 \%$; 23 commercial format shops facing tourists and residents, reaching $22.5 \%$, and 4 stores facing residents' lives, reaching $4 \%$.

Among the commercial formats facing tourists, there are 37 bars and tea bars, accounting for $49.3 \%$, followed by 9 ethnic clothing shops, accounting for $12 \%$, and 8 regional cultural handicrafts and cultural creative product shops, accounting for $10.6 \%$. Meanwhile the native products of the village have not been really developed, most of which are the native products (four famous snacks, nuts, etc.) that are common in the market, reaching $8 \%$.

Among the commercial formats facing tourists and residents, there are 11 grocery stores, accounting for $47.8 \%$, including 6 living supermarkets and 5 painting material supermarkets.

In the commercial format facing the life of residents, "clothing, food, housing, and transportation" cannot be completely satisfied[7]. It can be seen from the table that there are serious deficiencies in the business layout of Jiyangxi water street that involves residents' living needs. For example, there are no dry cleaners or repair shops. Whether it is an ancient tourist village or a famous historical and cultural village, once the label was removed, the essential attributes of traditional villages are still villages that satisfy people's need of living. Both the comfort and convenience of living need to be satisfied, so as to truly achieve the existence of a "people-oriented" village significance.

Table 3 Statistics of commercial shops in Jiyangxi water street, Pingshan Village

Function Head Middle End Remark

\begin{tabular}{|c|c|c|c|c|}
\hline \multicolumn{5}{|l|}{ Facing tourists } \\
\hline $\begin{array}{c}\text { Souvenirs\& } \\
\text { accessories shop }\end{array}$ & 2 & 6 & 0 & $\begin{array}{c}\text { Cultural and } \\
\text { creative shops, } \\
\text { handicraft shops }\end{array}$ \\
\hline Clothing store & 2 & 5 & 2 & $\begin{array}{c}\text { Ethnic clothing } \\
\text { store }\end{array}$ \\
\hline $\begin{array}{l}\text { Internet café, pool } \\
\text { room, KTV }\end{array}$ & 2 & 3 & 1 & \\
\hline Restaurants & 0 & 4 & 0 & $\begin{array}{l}\text { Clubhouse, } \\
\text { restaurants, fast } \\
\text { food, etc. }\end{array}$ \\
\hline BBQ & 1 & 2 & 2 & Outdoor BBQ \\
\hline Native products & 1 & 4 & 1 & \\
\hline Bar (tea bar) & 8 & 22 & 7 & $\begin{array}{c}\text { Bar, } \\
\text { coffee/water } \\
\text { bar, tea house, } \\
\text { etc. }\end{array}$ \\
\hline Total & 16 & 46 & 13 & \\
\hline
\end{tabular}

Facing tourists and residents

\begin{tabular}{|c|c|c|c|c|}
\hline Grocery shop & 2 & 4 & 5 & $\begin{array}{l}\text { Supermarket, } \\
\text { painting } \\
\text { material store, } \\
\text { etc. }\end{array}$ \\
\hline Dry cleaning & 0 & 0 & 0 & \\
\hline Food & 0 & 7 & 0 & Snacks \& drinks \\
\hline Pharmacy/Clinic & 0 & 1 & 0 & \\
\hline Communication & 0 & 1 & 0 & $\begin{array}{l}\text { Mobile phone } \\
\text { bill service hall }\end{array}$ \\
\hline Printing room & 0 & 1 & 0 & \\
\hline $\begin{array}{c}\text { Bank } \\
\text { (businessoffice) }\end{array}$ & 2 & 0 & 0 & \\
\hline Total & 4 & 14 & 5 & \\
\hline \multicolumn{5}{|c|}{ Facing residents } \\
\hline Barber Shop & 0 & 1 & 1 & \multirow{5}{*}{$\begin{array}{c}\text { Courier, sewing } \\
\text { shop }\end{array}$} \\
\hline $\begin{array}{l}\text { Agricultural } \\
\text { Supply }\end{array}$ & 0 & 1 & 0 & \\
\hline Resident services & 1 & 0 & 0 & \\
\hline $\begin{array}{c}\text { Car dealers, repair } \\
\text { shops }\end{array}$ & 0 & 0 & 0 & \\
\hline Total & 1 & 2 & 1 & \\
\hline Total & & 102 & & \\
\hline
\end{tabular}

In the field survey, it was learned from villagers' interviews that the peak tourist season in Pingshan Village lasts for 6 months, which are April, May, June, September, October, and November. Most businesses are open during the peak season. During the six months of the off-season, businesses is closed about $80 \%$ of the period. $50 \%$ of the commercial formats are operated by villagers and other half are operated by people outside the village. Therefore, during the off-season, the commercial of Pingshan Village is in a stagnant state and 
cannot facilitate the production activities of the villagers.

$90 \%$ of the commercial houses in the village locates in the ancient buildings in the village, and there are a large number of "ancient buildings" after the renovation of ancient buildings, which damages historical buildings and cultural relics. During the off-season, many villagers begin to "renovate" activities to expand the functional capacity of buildings, such as restaurants, bars, and hostels. But the true appearance of traditional villages has become "abstract". In the peak season for sketching, the village becomes "passionate". Students finish their daytime sketching activities and revel in bars, KTVs, and barbecue stalls in the village at night. This is nothing more than an ancient architectural village full of historical and cultural deposits. It was the current that hit the "heart" of the village. In this ancient architectural village full of historical and cultural deposits, this is nothing more than a current hitting the "heart" of the village.

Behind this rapid development, a group of people are bearing the cost of the "hormonal effect". The villagers who still retain farming and tea cultivation are restricted in their life in the village. This is reflected in the disturbance of work and rest, the obstruction of traffic, the distincet way of communication and so on. Villagers no longer have the living conditions that farmers should have. Faced with the impact of sketching students, more villagers are willing to choose to live behind closed doors. The scene of communication in the village carrying a hoe is also wiped out by the small benches of sketching. When Pingshan Village was restored to its original appearance during the off-season, it found that many lives were never going back.

\section{ANALYSIS OF THE SPATIAL CHARACTERISTICS OF THE COMMERCIAL CORE AREA OF PINGSHAN VILLAGE}

Integrating the overall topographic map and satellite image of Pingshan Village, combined with the aerial photos of the village from the field survey, this paper uses Depthmap software to summarize and analyze the spatial structure and spatial characteristics of Jiyangxi water street in Pingshan Village, Yixian County[8]. Also, this paper study the spatial changes and the connection between space and human management and activities through quantitative relationships.

\section{A. Analysis of integration}

Through the analysis of Depthmap spatial characteristics[9], it is concluded that the red and orange equiaxes with higher integration degree in the spatial integration analysis are basically distributed in the center of Jiyangxi water street (see Figure 4), that is, from the Shangqiao Pavilion to the surrounding of the Youqing Hall building. This overlaps with the actual location of the Jiyangxi business layout in Pingshan Village, thus verifying that the commercial business format functions and spatial characteristics are related to each other. Most comprehensive nodes are scattered in the site radiating 50 meters around the center of the bridge pavilion above the middle section of Jiyangxi water street. The blue axis is an area with relatively low spatial integration, distributed in the head and end section of Jiyangxi water street, where the traffic accessibility is poor. The integration of the Xiaqiao Pavilion at the entrance of the village and the Sangu Temple at the end of the village is low, because the roads passing through the Xiaqiao Pavilion and Sangu Temple are limited and tortuous. In order to better understand the relationship between the function of the business and the integration of the village water street, the Depthmap is used to compare the integration analysis map of local (R3) with the Jiyangxi water street overall (HH). The figure shows that the tourist nodes such as Baibu Hall, Youqing Hall, Hulujing, and Imperial Guard are all within the radius of the village and the core area of the water street. Field research found that the vicinity of Shangqiao Pavilion is a gathering place for villagers and tourists to rest and operate businesses.
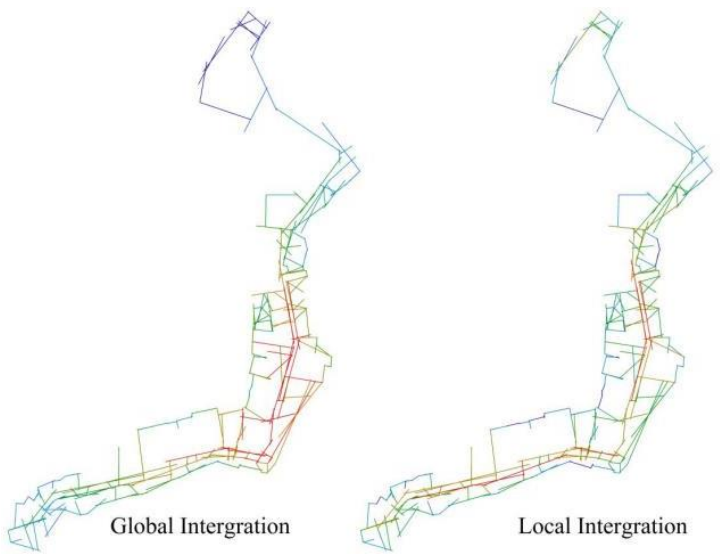

Fig 4 Analysis of integration degree of Jiyangxi water street

The space surrounded by buildings such as Youqing Hall and Pingshan Gongzhi creates a strong sense of spatial belonging. People clearly perceive the location in the whole village. The green axis indicates the low degree of integration is distributed in the Xiaqiao Pavilion section of Jiyangxi water street. The southeastern part of Jiyangxi water street is a relatively marginal area of the village. There are few streets in this area, the roads have large slopes and there are many broken roads. The northern area of Jiyangxi water street has the lowest degree of spatial integration, which is shown in a blue-green state in the picture.

\section{B. Analysis of connection value}

Through the analysis of the connection value in Depthmap, it is concluded that the axis with the highest connection value along JJiyangxi water street is located in the section from Xiaqiao Pavilion to Shangqiao Pavilion along Pingshan Mountain, and coincides with the axis with the highest degree of integration in the overall (see Figure 5). According to Depthmap analysis, the overall connection value of Jiyangxi water street in Pingshan Village is not high, and the areas with higher connection value along the water street are distributed in the two areas of the village entrance and the section from Youqing Hall to Xianyi Hall. From the figure of connection value analysis, the overall axis of Jiyangxi water street has more turning areas, and the space permeability is weak. Due to the high density of buildings on the side of the Water Street, people's sight is almost blocked. 


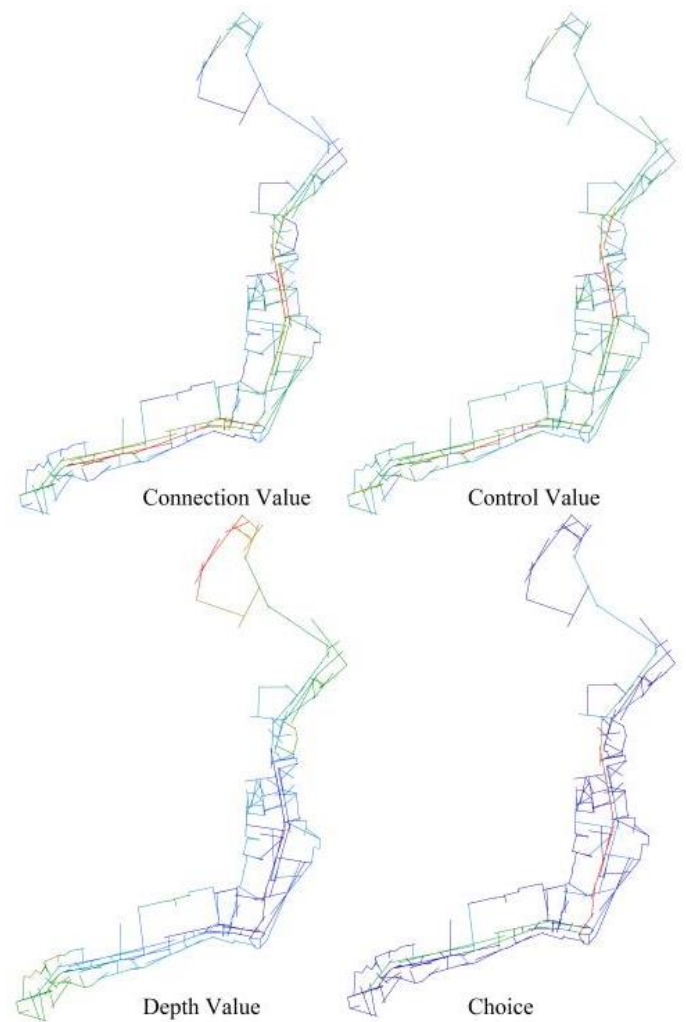

Fig5 Spatial analysis of Jiyangxi water street

\section{Analysis of control value}

The analysis of the control value through the space syntax Depthmap topology structure shows that the number of cold color axes is significantly more than that of warm color axes, which shows that the control value of this axis is the highest in the village from the fork between Youqing Hall to Bodhisattva Hall (see Figure 5). It reflects the relatively low control value between the various spaces of Jiyangxi water street, which is related to the many short roads in Pingshan Village.

\section{Analysis of depth value}

In the depth value analysis through space syntax, the location of the lowest depth value is in the core public area of Jiyangxi water street (see Figure 5). These streets are all located near Gongzhi, Baibu Hall and Youqing Hall in Pingshan Mountain. It can be seen from the figure that Jiyangxi water street is located in the northern area of Youqing Hall, which is farther from the public core area of Pingshan Village. The depth value gradually increases, and the slope of the terrain is also rising, so there is less contact with the outside world.

\section{E. Analysis of choice}

Through Depthmap's selectivity analysis, it is found that the axis section with the highest frequency in the core public area of Jiyangxi water street has the highest selectivity. As a stripshaped public space, its selectivity is much higher than that of the surrounding architectural streets, its traffic is also higher than that in the streets and lanes (see Figure 5). The section from the north of Shangqiao Pavilion to Youqing Hall is the central area of water street, which has a high degree of openness, accessibility and selectivity.

\section{F. Analysis of intelligibility}

In the Depthmap space syntax software, "select the local integration degree and the overall integration degree of linear analysis, and scatter through the $\mathrm{XY}$ axis. The distribution relationship of the $\mathrm{XY}$ axis scatter points can be used to derive the intelligibility of the axis system to measure the relationship between the local and the overall of the village."[2]

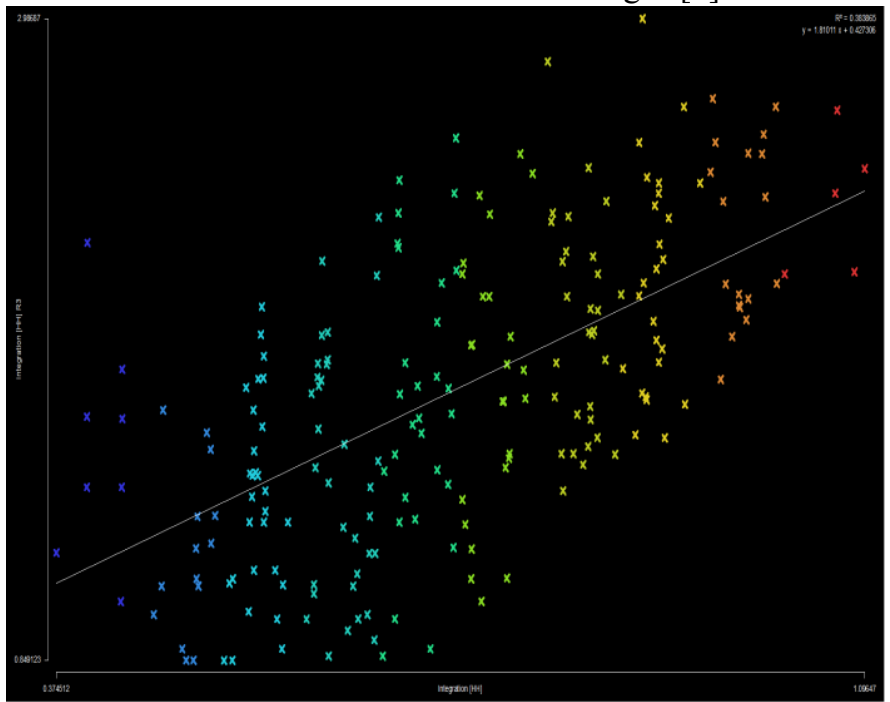

Fig. 6 Analysis of the spatial intelligibility of Jiyangxi water street

In the Depthmap software, "X-axis represents overall integration (integration $[\mathrm{HH}]$ ), $\mathrm{Y}$-axis represents local integration (Intergration[HH]R3), $\mathrm{R}^{2}$ represents intelligibility, and the blue dots on the lower left indicate lower intelligibility for numerical road axis, the red and yellow dots on the upper right indicate the road axis which is easier to understand. If the intelligibility exceeds 0.5 , it indicates that the spatial system is easier to understand, on the contrary, the spatial intelligibility is weaker. "[10]

The overall intelligibility of Jiyangxi water street obtained from the intelligibility analysis in Figure 6 is 0.38 , indicating that the spatial comprehensibility of Jiyangxi water street in Pingshan Village is weak, so it takes time for tourists and residents to form an impression of the entire village. The identification of Jiyangxi water street in Pingshan Village is relatively low, the street space is relatively tortuous, and the ancient building forms are relatively similar. The verification is consistent with the actual investigation.

The ancient buildings in the streets and lanes of Pingshan Village have high density and poor traffic accessibility due to factors such as defense functions and Feng Shui layout during construction. Due to the impact of the sketching business format, more and more villagers have initiated the selfconstruction behavior of antique buildings, but the government do not have a relatively systematically plan for this, which has caused irreversible destruction to the architectural order in the streets and the cultural texture of the streets and lanes. In addition, most of the newly built residential houses in the village are in the form of overthrowing and rebuilding of the 
original sites of ancient buildings in the Ming and Qing Dynasties, and the edge of the village near the traffic road outside the village and the edge of the village farmland. However, the road facilities of the village's streets cannot be extended and planned simultaneously, which increased the space depth value of the village streets, causing the experience objects to have a weak understanding of the environment of the streets and lanes of Pingshan Village.

According to the analysis of the spatial characteristics of Pingshan Village and Jiyangxi water street, the influence of residents and tourists on the development of traditional ancient villages has played a decisive role in recent years. The reason is caused by the tourism of Ping Shan Village as a sketching base. During the peak tourist season, sketching students (tourists) live and study in the village, and the content and path of their activities directly affect the economic development and morphological changes of the village. During the off-season of tourism, many residents will do improvement and construction work for the services of tourists, and a small number of residents will enjoy traditional folklore and cultural inculcation after farm work. Due to the contradictory relationship between the background of rapid economic development and the application of "fast food" in traditional spaces, forcing traditional villages focused on the development of an economy that can infinitely undertake the sketching business, ignoring objectively think about the relationship between the carrying capacity of historical and cultural villages and the speed of sustainable development.

\section{RESEARCH ON THE ADJUSTMENT STRATEGY OF SPATIAL AND BUSINESS FORMAT}

It can be seen from the business layout that satisfying tourists has evolved from "eating, drinking, traveling, shopping, and living" to "eating, drinking, traveling, shopping, living, and entertaining." Among them, "entertaining" accounted for 57.3\% of the format for tourists. In order to cater to the needs of college students, the structure of the format has formed an "unbalanced" state, and there are very few business formats that really need to export the cultural connotation of the village. College students are the inheritors of traditional culture. In the process of sketching and learning, traditional villages should export the village's excellent culture and attractions as cultural carriers to tourists. Therefore, in the layout of business formats, the establishment such as cultural and creative stores, cultural experience centers should be increased to develop an industrial chain for cultural inheritance. Combined the spatial layout with the analysis, it is found that the most integrated part, that is the the middle section of Jiyangxi water street should increase the establishment of cultural and tourism industries, and extend the entertainment industry as far as possible to the end of the street and the area with low building density. Integrate the shopping malls in the water street and divide the functions of commercial supermarkets, including convenience supermarkets (located at the entrance of the village, the middle of the water street, and around Sangu Temple), and painting materials supply supermarkets (located around the student hostel and at the end of the water street), a comprehensive souvenir supermarket (the middle section of water street, around the comprehensive parking lot), a supermarket for supply of agricultural products and agricultural tools (located at the entrance of the village and the end of water street), etc.

On the banks of Jiyangxi water street, the adjustment of business conditions is used to control the flow of people, the carrying capacity of ancient buildings, and water pollution. In this paper, Jiyangxi water street was divided into three sections for business adjustment: the head of street, the middle part, and the end of the street. It is possible to combine business types with spatial characteristics so as to comprehensively analyze and improve the economic development of the village, while meeting the life and production needs of the village situation and reducing the intensity of over-development of ancient buildings.

(1) As for the head of Jiyangxi water street, from the Xiaqiao Pavilion (the entrance of the village) to the Shangqiao Pavilion section, due to the weak spatial integration, weak control values, and low selectivity factors of the area, considering the carrying capacity, control force and guidance of the flow of people, the establishment of commercial formats takes villagers' lives and tourists' perception of village culture as the main function. The main construction content is the government-oriented business connotation, such as a comprehensive tea culture experience store that integrates tea picking, frying, tea culture as marketing content; Huizhou architectural culture experience store that integrates ancient architectural culture, Huizhou merchants spirit, Shu's ancestral hall and other cultural introductions and souvenirs as marketing content; payment service of communication,life, etc; a comprehensive store in the form of a supply and marketing agency with contemporary significance and so on.

(2) As for the middle part of Jiyangxi water street, from Shangqiao Pavilion to Youqing Hall section, due to the overall and local integration, selectivity, and control value of this area are at the highest point in the analysis, it shows the core role this section plays to the entire water street. In the format setting of this section, comprehensive consideration should be given to the relationship between the main role of villager and the object role of tourist, as well as the effective connection with the water street section. The proportion of the structure should be adjusted in a balanced manner. In terms of content, the proportion of "entertainment" formats should be weakened, the quantity should be controlled, and the quality should be improved, mostly with quiet water bars for communication and relaxation. Also the characteristic elements of local opera need to be excavated, combined with tea culture, establishing stage and mini theater facilities. The local specialty store should integrate well-known domestic specialty products and local specialty products in Huangshan and Pingshan Villages, with packing those products to enhance the value of specialty products. Souvenirs and clothing shops can add cultural handicrafts and batik workshops and other traditional cultural experience shops, appropriately expand the content of the post office, family-style floral art gallery, sketching thematic works exhibition hall and special bookstores that use culture as the carrier to facilitate life in the original business functions. 
(3) As for the end of Jiyangxi water street, from Youqing Hall to Sangu Temple, due to the low degree of integration and selection in this area, the frequency of visitors' arrival and passage is low. In the format setting, it is more about serving the life and production of the villagers, expanding the format of life and production on the basis of the original format function, such as farm tool experience store, seed science store, agricultural technology service point, animal husbandry clinic, agricultural product markets, creative markets, painter tool shops, etc.

\section{CONCLUSION}

This paper conducts relevant research and algorithm development from three aspects: Pingshan Village POI data usage and analysis, Jiyangxi water street spatial feature extraction and analysis, and Jiyangxi water street business status survey data analysis. On the basis of analyzing the spatial characteristics and POI data of traditional villages, the nuclear density calculation formula was used to calculate the plane POI nuclear density of Pingshan Village and presented in a graph. The obtained POI data of Pingshan Village was sorted out and the classification of the POI data of Pingshan Village was summarized. This paper uses arcGIS to analyze and study the spatial pattern of Pingshan Village[11], uses depetmap to analyze the spatial layout and spatial characteristics of Jiyangxi water street, the commercial core area of Pingshan Village, analyzes and summarizes the current situation and restrictive factors of the development of spatial linkage business in Pingshan Village, then puts forward development suggestions and some strategies[12]. The research results show as follows.

In terms of research methods and calculation methods, it is more intuitive that this paper uses the kernel density estimation method to analyze the overall spatial pattern of Pingshan Village, and more objective to analyze the natural form and spatial characteristics of Pingshan Village and Jiyangxi water street by arcGIS software and Depthmap software[13]. The analysis above shows the importance of Pingshan Village's geography in the natural and historical conditions, the influence of tourism economy on the spatial characteristics of Pingshan Village, and the exploration of the direction of harmonious development of tourism economy and historical traditional villages, revealing the coupling connection of the village's spatial relationship and business layout .

From the analysis of the core segment of the commercial format of Pingshan Village, the strip-shaped commerce of Jiyangxi water street in Pingshan Village carries the core of the tourism economic format in the village. Combining the advantages and disadvantages of the current development situation, the importance of the development of Pingshan Village's business format and the necessity of business format adjustment are analyzed. The overall economic development of Pingshan Village mainly relies on the platform of the sketching base for multiple distribution, but the emergence of new industries and new economies and the spatial integration of traditional villages are issues that require comprehensive consideration. Because the positioning of the tourism industry stems from the ornamental value of the space within the site, if the traditional culture is worn out in the village because the businesses of sketching services (such as accommodation, catering, etc.) occupy the core ornamental flow, then the value of this tourism will be greatly reduced. New industries (such as creative bazaar, multimedia services, etc.) and new economies (such as modern agriculture, creative factories, etc.) will be shown in traditional villages with the development of the times. How to superimpose historical culture with new culture to generate a greater value system is the core value of rural revitalization.

The village space of Pingshan Village is in the form of internal defense and external inclusiveness. The internal buildings of the streets are densely packed, and the space accessibility of the streets are poor. Ancient residential buildings were used for commercial purposes without considering the commercial carrying capacity of historical buildings and the operation cost of maintenance. The historical buildings were simply pushed into new antique buildings, resulting in disharmonious architectural forms in the village and unreasonable spatial layout. Based on the combination of space utilization and business layout, new buildings are directed radiating the periphery of the village, and the space of historical buildings is preserved and displayed to maintain the cultural heritage[14] .

All in all, this paper analyzes the overall spatial distribution pattern and POI data of Pingshan Village from a macro level, and provides certain suggestions and references for the future layout of traditional villages. As for the issue that development of traditional villages' space and business status without considering the evolution of time and space dynamics, the subsequent research will try to analyze the historical evolution process and future development trend of traditional villages in Anhui Province based on the acquisition of remote sensing data in different eras, and provide scientific data for improving the space optimization and economic development of traditional villages, so as to improve the inheritance and protection of traditional villages in the new era.

Through analyzing the characteristics of tourism development and the spatial structure of the villages around Jiyangxi water street, which is a representative of Pingshan Village, this paper puts forward suggestions on the coupling of space and business. Those suggestions holds the purpose of inheriting and protecting traditional villages to specifically implementing business adjustments and space utilization. In the further implementation of rural revitalization, the business optimization strategy of Ping Shan Village is used as a fulcrum to try to radiate the business layout adjustment of similar traditional villages, and the methodological path of spatial characteristics analysis is implanted in the traditional villages with cultural localities to couple the advantages and disadvantages of spatial layout with the reasonable layout of business, so as to promote the economic development of traditional ancient villages in practice and thus achieve the good goal of traditional culture living This will promote the economic development of traditional ancient villages, and thus achieve the beautiful goal of traditional cultural heritage and effective rural revitalization. 


\section{FUND PROJECT}

This work is supported by Anhui Philosophy and Social Science Planning Project "Coupling Analysis of Spatial Features and Business Layout of Traditional Villages in Anhui Province" (AHSKQ2018D72)

\section{REFERENCES}

[1] Zhou Jianming.Traditional Chinese Villages:Protection and Development[M].Beijing:China Architecture \& Building Press,2014

[2] Xu Hui,Zhao Hesheng,Liu Feng.Preliminary Study in Syntactical of the Spatial Form of Traditional Villages:A Case Study of Jiangshan HejiaWujia Village in Guchen Town,Gaochun County,Nanjing. Modern Urban Research,2016 (1):24-29

[3] GAO Feng.Study on Space Syntax and Space System of Lane in Southern Anhui Village - Take Anhui Nanping Village as an example[J].Development of Small Cities \& Towns,2003(11):42-44.

[4] Podesta Cristian,Coleman Natalie,Esmalian Amir,Yuan Faxi,Mostafavi Ali. Quantifying community resilience based on fluctuations in visits to points-of-interest derived from digital trace data.. Journal of the Royal Society, Interface,2021,18(177).

[5] Brockmann D,Hufnagel L,Geisel T. The scaling laws of human travel. Nature,2006,439(7075).

[6] YE Maosheng,LI Zao,WANG Decai.RESEARCH ON The Spatilal Strucyure Of Traditional Villagesin Southern ANHUI From The Perspective Of Beautiful Villages Construction. Industrial Construction, 2018,48(05):89-94+88.

[7] ZHOU Xiao-feng,LU Song,CHEN Si-yi,SONG Xing-zhen.On the Ancient Hongcun Village from the Perspective of Tourist Commercialization. Journal of Shijiazhuang University, 2013,15(06):5157.

[8] Reza Askarizad,Hossein Safari. Investigating the role of semi-open spaces on the sociability of public libraries using space syntax (Case Studies: Sunrise Mountain and Desert Broom Libraries, Arizona, USA). Ain Shams Engineering Journal,2020,11(1).

[9] Khan Naimat Ullah,Wan Wanggen,Yu Shui,Muzahid A. A. M.,Khan Sajid,Hou Li. A Study of User Activity Patterns and the Effect of Venue Types on City Dynamics Using Location-Based Social Network Data. ISPRS International Journal of Geo-Information,2020,9(12).

[10] Chen Zhe,Cheng Shidan.Research on the Syntax of Public Space in Traditional Villages:Taking Zhuqiao Village in Jinxi County of Jiangxi Province as an Example. Huazhong Architecture,2020,38(08):62-65.

[11] Brockmann D,Hufnagel L,Geisel T. The scaling laws of human travel. Nature, 2006,439(7075).

[12] WANG Xingyi,GUAN Xin,DING Jingjing.Spatial Distribution of Traditional Villages in Anhui Province and Its Formation[J].Journal of Anhui Agricultural University(Social Sciences Edition),2017,26(02):1925 .

[13] Mark J. Nieuwenhuijsen,Haneen Khreis,Margarita Triguero-Mas,Mireia Gascon,Payam Dadvand. Fifty Shades of Green: Pathway to Healthy Urban Living. Epidemiology,2017,28(1).

[14] B. Anand,D. Karunanidhi,T. Subramani,K. Srinivasamoorthy,M. Suresh. Long-term trend detection and spatiotemporal analysis of groundwater levels using GIS techniques in Lower Bhavani River basin, Tamil Nadu, India. Environment, Development and Sustainability: A Multidisciplinary Approach to the Theory and Practice of Sustainable Development, 2020, 22(4).

[15] Arquiñigo C M, Encinas A I D, Arquiñigo N M. Spatial planning of the timber industry and the social-environmental and economic impact in Pucallpa-Ucayali (Peru), 2000-2019[J]. WSEAS Transactions on Environment and Development, 2021, 17: 583-594.

[16] Yasar Guneri Sahin, Diaa E. Fawzy, HaReS: Real-time hazard reporting and loss estimation system, international Journal of Electrical Engineering and Computer Science (EEACS), Volume 1, 2019, pp. 24-31.

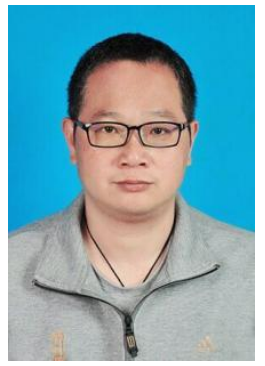

LI Chuntao was born in Anhui, China, in 1972. He studied in Nanjing Forestry University and received he Master's degree of Landscape architecture. Since graduated, he worked in Anhui Agricultural University, Hefei, Anhui. He has published more than twenty papers. His research interests are includedgarden landscape design.

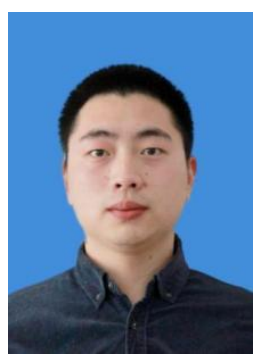

BI Huiyu was born in Anhui, China, in 1992. Since 2019, he studied in Anhui Agricultural University, Hefei, Anhui.He has published three papers. His research interests are included garden landscape design, protection and inheritance of traditional villages.

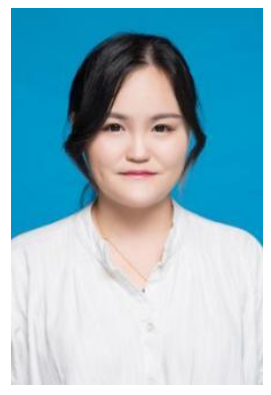

CHEN Zhenhua was born in Anhui, China, in 1985. She studied in Hefei University of Technology and received her Master's degree of Design Art. Since graduated, he worked in Anhui Xinhual University, Hefei, Anhui. She has published more than ten papers. His research interests are includedgarden landscape design. CHEN Zhenhua is corresponding author, Email: chen_zhenhua@axhu.edu.cn

\section{Creative Commons Attribution License 4.0 (Attribution 4.0 International, CC BY 4.0)}

This article is published under the terms of the Creative Commons Attribution License 4.0 https://creativecommons.org/licenses/by/4.0/deed.en US 